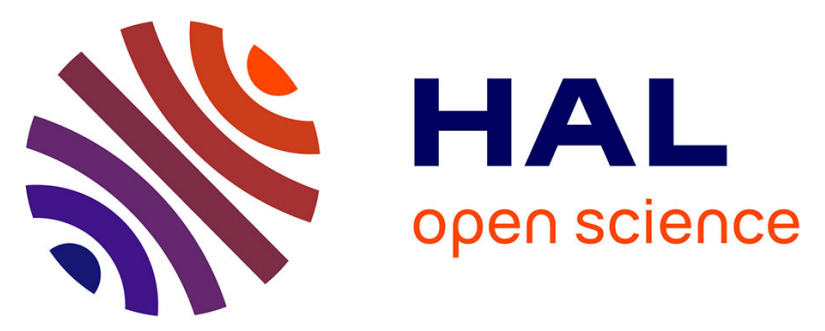

\title{
First assessment of triclosan, triclocarban and paraben mass loads at a very large regional scale: case of Paris conurbation (France).
}

Johnny Gasperi, Darine Geara, Catherine Lorgeoux, Adèle Bressy, Sifax

Zedek, Vincent Rocher, Antoine El Samrani, Ghassan Chebbo, Régis

Moilleron

\section{To cite this version:}

Johnny Gasperi, Darine Geara, Catherine Lorgeoux, Adèle Bressy, Sifax Zedek, et al.. First assessment of triclosan, triclocarban and paraben mass loads at a very large regional scale: case of Paris conurbation (France).. Science of the Total Environment, 2014, 493, pp.854-61. 10.1016/j.scitotenv.2014.06.079 . hal-01063311

\section{HAL Id: hal-01063311 \\ https://hal-enpc.archives-ouvertes.fr/hal-01063311}

Submitted on 23 May 2018

HAL is a multi-disciplinary open access archive for the deposit and dissemination of scientific research documents, whether they are published or not. The documents may come from teaching and research institutions in France or abroad, or from public or private research centers.
L'archive ouverte pluridisciplinaire HAL, est destinée au dépôt et à la diffusion de documents scientifiques de niveau recherche, publiés ou non, émanant des établissements d'enseignement et de recherche français ou étrangers, des laboratoires publics ou privés. 


\section{FIRST ASSESSMENT OF TRICLOSAN, TRICLOCARBAN AND PARABEN MASS LOADS AT A VERY LARGE REGIONAL SCALE: CASE OF PARIS CONURBATION (FRANCE)}

Johnny Gasperi $^{1 *}$, Darine Geara ${ }^{1,2}$, Catherine Lorgeoux ${ }^{1,3}$, Adèle Bressy ${ }^{1}$, Sifax Zedek $^{1}$, Vincent Rocher ${ }^{4}$, Antoine El Samrani ${ }^{5}$, Ghassan Chebbo ${ }^{1}$, Régis Moilleron ${ }^{1 *}$

1. Université Paris-Est, LEESU, UMR MA 102 - AgroParisTech, 61 avenue du Général de Gaulle, 94010 Créteil Cedex, France.

2. Lebanese Atomic Energy Commission, Airport Highway BP 1182 81, Riad El-Solh 1107 2260, Beirut (Lebanon).

3. Université de Lorraine, CNRS, CREGU, GeoRessources laboratory, Faculté des Sciences et Techniques - Campus des Aiguillettes BP 70239, 54506 Vandoeuvre-lès-Nancy, France.

4. SIAAP, Direction du Développement et de la Prospective, 82 avenue Kléber, 92700 Colombes, France.

5. Doctoral School, PRASE Lebanese University, Campus Hadath-BP5, Beirut (Lebanon).

* Corresponding authors: Fax: +33 (0)1 4517 16 27, e-mail: gasperi@u-pec.fr, moilleron@u-pec.fr 


\begin{abstract}
The objective of this study was to examine the occurrence of parabens ( 5 congeners), triclosan (TCS) and triclocarban (TCC) at the scale of the Parisian sewer network and to provide representative knowledge on these compounds in France for a large area. For this purpose and in collaboration with the Parisian public sanitation service (SIAAP) in charge of the collect and treatment of the Parisian wastewater, this study focused on seven main sewer trunks of the Paris conurbation, accounting for $1900000 \mathrm{~m}^{3} \mathrm{~d}^{-1}$, i.e., about 8 million inhabitants. Concentrations lying in the $2000-20000 \mathrm{ng} \mathrm{l}^{-1}$ ranges were found in wastewater, confirming the ubiquity of parabens, TCS and TCC in our environment and household products. Parabens (> 97\%) and to a lesser extent TCS (68\% in median) were mainly associated to the dissolved fraction, as demonstrated by low $K_{D}$ and $K_{O C}$ values. For the first time, this study also evaluated the pollutant mass loads per population equivalent (PE) of parabens, TCS and TCC at the large and representative scale of the Parisian conurbation. Hence, the median mass loads varied from 176 to $3040 \mu \mathrm{g} \mathrm{PE}^{-1} \mathrm{~d}^{-1}$ for parabens and from 26 to $762 \mu \mathrm{g} \mathrm{PE}^{-1} \mathrm{~d}^{-1}$ for TCS and TCC. Based on these results and according to the assumptions done, the extrapolation of the mass loads at the national scale pointed out an annual mass loads between 51.8 and $100.7 \mathrm{t} \mathrm{y}^{-1}$ for methyl paraben (MeP) and between 11.2 and $23.5 \mathrm{t} \mathrm{y}^{-1}$ for TCS. Mass loads per equivalent habitant and national mass loads are both extremely relevant and innovative data. Contrary to other countries, such data are nowadays rather difficult to gain in France and no enquiry nor database provide access to information on the use and production of these chemicals. Since cosmetic industries are voluntarily and fully engaged in the substitution of parabens, triclosan and triclocarban in personal care product, this study could constitute a "time reference status" which could be used as a basis for future monitoring.
\end{abstract}

\title{
Keywords
}

Parabens, triclosan, triclocarban, wastewater, loads, population equivalent 


\section{Introduction}

As a result of human activities and consumption of a large array of chemicals, numerous contaminants including pharmaceuticals and personnel care products (PPCPs), flame retardants, endocrine disruptors and priority pollutants as defined by the European water framework Directive are present in wastewater (Berge et al., 2013; Gasperi et al., 2008a; Kolpin et al., 2002; Lee et al., 2005; Paxeus, 1996). Among them, PPCPs are of increasing concerns owing to their ubiquities in environmental compartments, their persistent inputs, and their potential threat to environment and human health (Halling-Sorensen et al., 1998; Lee et al., 2005; Liu and Wong, 2013; Onesios et al., 2009). Among the most concerned PPCPs, preservative agents such as parabens (esters of p-hydroxybenzoic acid), triclosan (TCS, 5chloro-2-2,4-dichlorophenoxy) and triclocarban (TCC, 3,4,4'-trichlorocarbanilide) are commonly employed in food, cosmetic (soaps, shampoos, detergents, toothpastes, etc.) and pharmaceutical products. These compounds are antiseptic, bactericidal and fungicidal agents. The esters of p-hydroxybenzoic acids with alkyl and aryl subsistent including methyl- (MeP), ethyl- (EtP), propyl- (PrP), isobutyl- (IsoBuP), butyl-(BuP) and benzyl-paraben (BzP) are mostly used in personal care products. Short chain parabens (methyl-, ethyl- and propyl-) are mainly used in liquid personal care products (liquid soap, etc.), while long chain congeners (butyl- and isobutyl-) are mostly employed in creams (Eriksson et al. 2009). According to an enquiry led by Tavares et al. (2009) in Spain on 215 personal care products, 99\% of creams and 77\% of cleansing lotions and make-up removers contained parabens. In France in 2009, about 7000 personal care products or formulations containing MeP were marketed against $3000-5$ 000 products containing the remaining paraben esters (Mintel database, Global Market Research and Market Insight (Mintel, 2013)). Similarly, 860 products containing TCS were listed against only 4 containing TCC. Data on their mass loads are nevertheless not available. 
For parabens, the maximum allowable concentrations is $1 \%(\mathrm{w} / \mathrm{w})$ (Tavares et al., 2009). According to EC Scientific Committee on Consumer Safety (SCCS) updated opinion in 2013 (SCCS, 2013), ethyl- and methyl-parabens are considered safe at a maximum concentration of $0.4 \% \mathrm{w} / \mathrm{w}$ for single and $0.8 \% \mathrm{w} / \mathrm{w}$ for mixtures of esters. Following the recent debate on the safety of the use of parabens as preservatives in cosmetics in 2013, and based on the last SCCS opinion, the European Commission (EC) decided to ban benzyl-, pentyl-, isopropyl-, isobutyl- and phenyl-parabens. The combined use of butyl- and propyl-parabens is to be limited to $0.19 \% \mathrm{w} / \mathrm{w}$ (as esters).

Similarly to parabens, TCS is used in a large array of products including soaps, deodorants, toothpastes and can be also used as additives for plastics or food packaging and textiles whereas TCC has a more restricted use (soaps or body washes). The main application of TCS is in PPCPs (85\% of total production) against $10 \%$ for textile or food packaging (Bedoux et al., 2012). Recently in 2010, the use of TCS as additive in food plastic packaging was banned by the EC 2010/169/EU. For TCS and TCC, up to $0.3 \%(\mathrm{w} / \mathrm{w})$ and $5 \%(\mathrm{w} / \mathrm{w})$ are respectively added to a variety of consumer products in the US (Halden and Paull, 2005).

For these compounds, a particular attention have been paid to their fate within wastewater treatment plants (WWTP) in different areas (Gracia-Lor et al., 2012; KasprzykHordern et al., 2009; Miege et al., 2009; Sim et al., 2010). However, today, data on their production and consumption are confidential and thus rather difficult to obtain. As an alternative way, some experimental studies estimated the mass loads of triclosan and parabens in wastewater at different scales (houses, neighborhood or catchments) (Eriksson et al., 2009; Lindstrom et al., 2002; Palmquist and Hanæus, 2005; Wind et al., 2004). For parabens, only Eriksson et al. (2009) in Denmark evaluated individual paraben mass loads in greywater between 30 and $275 \mu \mathrm{g}$ inhab ${ }^{-1} \mathrm{~d}^{-1}$ at the scale of 120 resident buildings. In Sweden, Palmquist and Hanaeus (2005) evaluated the load of triclosan at $200 \mu \mathrm{g}$ per population equivalent and per 
day $\left(\mu \mathrm{g} \mathrm{PE}^{-1} \mathrm{~d}^{-1}\right)$ in greywater and $100 \mu \mathrm{g} \mathrm{PE} \mathrm{P}^{-1} \mathrm{~d}^{-1}$ in blackwater for a block of 47 small onefamily houses consisting of 169 persons. At a larger scale, Lindström et al. (2002) reported in Switzerland triclosan mass loads at $412 \mu \mathrm{g}_{\text {inhab }} \mathrm{d}^{-1}\left(190-750 \mu \mathrm{g}\right.$ inhab $\left.^{-1} \mathrm{~d}^{-1}\right)$ in influents from WWTPs serving populations between 4500 and 19000 persons. In spite of these significant experimental inputs, knowledge on the occurrence and mass loads of these chemicals are deeply needed since data are rather limited for both compound families and concerned quite small areas. Due to high short-term variation in flow and pollutant concentrations, working at a too small scale can lead to potential bias to get a representative mass load evaluation. In addition, and due to the emerging concerns and the media coverage of parabens and triclosan as potential endocrine disruptors, a consumption decrease of personal care products containing parabens, TCS and TCC is expected. To date, no data show this trend and no study fixed an initial state.

In this context, this study was therefore launched as part of the OPUR (Observatory of Urban Pollutants in Paris) research program, with the objective of examining the occurrence of parabens, TCS and TCC at the scale of the Parisian sewer network and to provide representative data on these compounds in France at the scale of the Parisian conurbation. For this purpose and in collaboration with the Parisian public sanitation service (SIAAP) in charge of the collect and treatment of the Parisian wastewater, this study focused on the main seven sewer trunks of the Paris conurbation (Figure 1). The total flow was estimated at $1900000 \mathrm{~m}^{3} \mathrm{~d}^{-1}$, corresponding to about 8 million inhabitants, i.e., $13 \%$ of the national population. At this scale, the objectives of the present study are i) to assess the occurrence and the concentration ranges of parabens, TCS and TCC in the Parisian wastewater, ii) to examine their partitioning between the dissolved and particulate phases, iii) to evaluate pollutant mass loads per population equivalent (PE) at a large scale area and finally iv) to extrapolate mass loads at a national scale.

By investigating the occurrence and mass loads of these chemicals at the Parisian and then at the national scales, this study delivers new and original data on the actual consumption 
of these chemicals in developed countries such as France. This study also provides a reference status which could be used as a basis for future monitoring and for setting sustainable policies.

\section{Materials and methods}

\subsection{Site description and sampling strategy}

The main seven Parisian sewer trunks were considered; the 5 deserving the Seine Aval wastewater treatment plant (WWTP): Saint-Denis Achères (SDA), Clichy Achères Argenteuil (CAA), Clichy Achères Bezons (CAB), Sèvres Achères Nanterre (SN), Sèvres Achères Rueil (SR), and those deserving the Seine Amont (SAM) and Marne Aval (MAV) WWTPs. The Parisian sewer network is combined and all campaigns were performed during dry weather periods. The main characteristics of these sewer trunks are given in Table 1. Depending on the sewer trunks, the daily average wastewater flows range from 49500 to $458000 \mathrm{~m}^{3} \mathrm{~d}^{-1}$. At a daily scale, the total volume is about $1900000 \pm 79400 \mathrm{~m}^{3}$ corresponding to $9485000 \pm 581$ 900 PE. The Seine Aval WWTP is one of the greatest in Europe collecting about $1452000 \pm$ $54800 \mathrm{~m}^{3} \mathrm{~d}^{-1}$, i.e., $6800000 \pm 389000$ PE. The other two WWTPs respectively collect 49500 \pm 4600 and $398000 \pm 48500 \mathrm{~m}^{3} \mathrm{~d}^{-1}$. Four sampling campaigns were carried out in April, May, and December ( $\mathrm{n}=2,1^{\text {st }}$ and $2^{\text {th }}$ December) 2010. Systematically, 24h-flow weight average samples were considered. Samples were collected using automatic and refrigerated samplers from SIAAP, equipped with Teflon ${ }^{\circledR}$ pipe.

\subsection{Analytical procedure}

\section{Wastewater quality parameters}

For each sample, wastewater quality parameters, such as total suspended solids (TSS), chemical and biochemical oxygen demands (COD and $\left.\mathrm{BOD}_{5}\right)$, ammonium $\left(\mathrm{NH}_{4}^{+}\right)$, total Kjeldahl nitrogen (TKN), total phosphorous (Ptot) and orthophosphates $\left(\mathrm{PO}_{4}{ }^{3-}\right)$, were analyzed by the internal SIAAP laboratory, a laboratory certified by the French Ministry of the Environment, i.e., COFRAC (French Accreditation Committee). Analyses were then performed 
according to the French (AFNOR) or International (ISO) standard methods (Supporting Table 1). Additionally, dissolved (DOC) and particulate organic (POC) carbons were respectively analyzed in duplicate via a Shimadzu TOC-Vws and rapid cube system (Elementar Analysen system $\mathrm{GmbH}$ ). Wastewater quality parameters were measured in order (i) to determine the representativeness of our sampling campaigns by comparing our results to those of the annual database of SIAAP, (ii) to evaluate population equivalent (with respect to TKN levels) and (iii) to establish whether it exists a relationship between wastewater quality parameters and pollutant concentrations. Those results are provided in Supporting Table 2.

\section{Parabens, triclosan and triclocarban analysis}

Height compounds were monitored, including 6 parabens (MeP, EtP, PrP, BzP, BuP and $\mathrm{BuP}$ ), TCS and TCC. The protocol is here briefly described but more analytical details can be found elsewhere (Geara-Matta, 2012; Geara-Matta et al., 2011) and also in Supporting Table 3. After homogenization of samples and filtration on glass fiber filters (GF/D $2.7 \mu \mathrm{m}$ and $\mathrm{GF} / \mathrm{F} 0.7 \mu \mathrm{m}), 100 \mathrm{ml}$ of the dissolved phase were acidified to $\mathrm{pH} 2-3$ with sulfuric acid $98 \%$ (40 $\mu \mathrm{l}$ for $100 \mathrm{ml})$ and spiked with two surrogate standards (PrP-d4 and TCS-d3, CDN isotopes). Triclosan, triclocarban and parabens were isolated from wastewater by solid phase extraction using Oasis HLB® cartridges $(6 \mathrm{ml}, 200 \mathrm{mg}$, Waters $)$. The cartridges were preconditioned with $10 \mathrm{ml}$ of methanol and $10 \mathrm{ml}$ of ultra-pure water. After sample loading at a flow rate of $1 \mathrm{ml} \mathrm{min}^{-1}$, cartridges were washed with $2 \mathrm{ml}$ of ultra-pure water and $200 \mu \mathrm{L}$ of methanol, dried under vacuum and eluted with $10 \mathrm{ml}$ of methanol. Finally, the eluates were spiked with internal standards (TCC-d4 and MeP-d4, CDN isotopes), dried under a gentle stream of $\mathrm{N}_{2}$, and finally reconstituted in $1 \mathrm{ml}$ of mobile phase.

For solids, the particles (about $100 \mathrm{mg}$ ) were first microwave extracted (Multiwave 3000®, Anton Paar) with $20 \mathrm{ml}$ of dichloromethane/methanol (90:10, v/v) and spiked with similar surrogate standards over a 30 min cycle. Two successive extractions were performed. 
After $\mathrm{N}_{2}$ drying, each aliquot (300 $\mu$ l of heptane) was purified on Oasis HLB® cartridges (6 ml, $200 \mathrm{mg}$, Waters).

Parabens, triclosan and triclocarban were analyzed by UPLC-MS/MS in negative mode using an Acquity UPLC system (Waters), coupled to a triple quadrupole TQD (Waters). An Acquity UPLC BEH C18® column $(1.7 \mu \mathrm{m} \times 2.1 \mathrm{~mm} \times 100 \mathrm{~mm})$ maintained at $40^{\circ} \mathrm{C}$, fitted with a guard column (4 $\mathrm{mm} \times 2.0 \mathrm{~mm} \mathrm{C18,} \mathrm{Phenomenex),} \mathrm{was} \mathrm{used} \mathrm{to} \mathrm{achieve} \mathrm{the}$ chromatographic separation. The injected volume was $10 \mu \mathrm{L}$. The mobile phases A and B consisted, respectively in ultra-pure water (5 mM NH4OAc) and methanol (5 mM NH4OAc). The quantification was assessed by internal calibration: MeP-d4 for MeP, PrP-d4 for EtP, PrP, $\mathrm{BuP}$, IsoBuP and BzP, TCC-d4 for TCC and TCS-d3 for TCS. Recoveries of surrogate and internal standards, as well as those of the targeted compounds for the dissolved phase are given in Supporting Table 3.

According to this analytical procedure, the limits of quantification (LOQ) ranged between 46 and $56 \mathrm{ng}^{-1}$ for parabens, and were respectively equal to 220 and $58 \mathrm{ng} \mathrm{l}^{-1}$ for TCS and TCC for dissolved phase $(100 \mathrm{ml})$. For particles $(100 \mathrm{mg})$, LOQs were evaluated at 0.02 $\mathrm{mg} \mathrm{kg}^{-1}$ for parabens, 0.15 and $0.02 \mathrm{mg} \mathrm{kg}^{-1}$ for TCS and TCC.

\subsection{Load calculation}

\section{$\underline{\text { Load calculation per equivalent habitant }}$}

To establish loads of parabens, TCS and TCC per PE and per day, the population equivalent had to be determined. The population equivalent or unit per capita loading was determined by using TKN levels rather than $\mathrm{BOD}_{5}$ ones (biological oxygen demand, 1 population equivalent equals $60 \mathrm{~g} \mathrm{BOD}_{5} \mathrm{~d}^{-1}$ ). Indeed, TKN in wastewater exclusively results from physiological emissions (Vienneras, 2001) and $80 \%$ of TKN is present in dissolved form (Thoburn, 1984). As a consequence, this parameter can be taken into consideration for an

improved evaluation of PE. Therefore one PE was defined as the load of 12 g.inhab $^{-1}$ of 
dissolved TKN per day (Gasperi et al., 2008b). For each campaign (j), mass loads (Loads ${ }_{i}^{j}$ ) were then calculated for each compound (i) as follows:

Loads ${ }_{i}^{\mathrm{j}}\left(\mu \mathrm{g} \mathrm{PE}^{-1} \mathrm{~d}^{-1}\right)=12\left(\mathrm{~g}^{\mathrm{TKN}}\right.$ per inhabitant per $\left.\mathrm{d}\right) \times \frac{\left[\mathrm{X}_{\mathrm{i}}\right]\left(\mu \mathrm{g} \mathrm{m} \mathrm{m}^{-3}\right)}{\left[\mathrm{TKN}_{\mathrm{j}}\right]\left(\mathrm{g} \mathrm{TKN} \mathrm{m}^{-3}\right)} \quad$ Equation 1

Where $\left[\mathrm{X}_{\mathrm{i}}\right]$ was the concentration of the given compound (i) in $\mu \mathrm{g} \mathrm{m}^{-3}$ and $\left[\mathrm{TKN}_{\mathrm{j}}\right]$ the concentration of dissolved TKN for the considered campaign (j) in $\mathrm{g} \mathrm{TKN} \mathrm{m}^{-3}$.

\section{$\underline{\text { Load calculation at the national scale }}$}

The mass loads of parabens, TCS and TCC were also estimated at the national scale. Therefore, two methods were applied. The first method considered that one population equivalent, as defined in this paper, is equal to 1 inhabitant and thus evaluated national loads on the basis of the French population (65 450000 inhabitants in 2012). For this method, the $\mathrm{d} 10$ and $\mathrm{d} 90$ percentiles, as well the median mass loads per equivalent habitant were considered $(\mathrm{n}=28)$, leading to $\mathrm{d} 10-\mathrm{d} 90$ and median national loads. The second method assessed the total pollutant loads $\left(\mathrm{g} \mathrm{d}^{-1}\right)$ discharged in the Parisian sewer for 8 million inhabitants for the four campaigns and the national loads were then proportionally evaluated. Since only four campaigns were performed, minimal and maximal values along with the average mass loads at the national scale were given.

\section{Results and discussion}

\subsection{Concentrations of parabens, triclosan and triclocarban in wastewater}

The total concentrations of parabens, TCS and TCC in wastewater are illustrated in Figure 2. Mean concentrations \pm standards deviations $(\mathrm{SD})$ on the basis of the four campaigns performed are shown for each sewer trunk. Numeric results are available in Supporting Table 4. Out of the height compounds monitored, benzyl-paraben was never detected in both dissolved and particulate phases $\left(<52 \mathrm{ng}^{-1}\right.$ for dissolved and $<0.02 \mathrm{mg} \mathrm{kg}^{-1}$ for particulate phases) whereas the remaining compounds were systematically detected in dissolved phase and 
to a lesser extent in particulate phase (60\% of occurrence for EtP and PrP, $40 \%$ for BuP). This is in accordance with results reported by Eriksson et al. (2009) for greywater, indicating that short chain parabens (MeP, PrP and EtP) are detected in 83-97\% of samples whereas long chain parabens (BuP and IsoBuP) were found less frequently.

Wastewaters were featured by the predominance of $\mathrm{MeP}$, with total concentrations ranging from 10300 to $20100 \mathrm{ng} \mathrm{l}^{-1}$ (first and last percentiles, d10-d90, n=28), followed by $\operatorname{EtP}\left(2670-4670 \mathrm{ng}^{-1}\right), \operatorname{PrP}\left(2440-3980 \mathrm{ng} \mathrm{l}^{-1}\right)$ and TCS $\left(2140-5260 \mathrm{ng}^{-1}\right)$. BuP showed an intermediate behavior with concentrations lying in the $450-1280 \mathrm{ng} \mathrm{l}^{-1}$ range while IsoBuP and TCC concentrations were far lower (98 - $230 \mathrm{ng} \mathrm{l}^{-1}$ for IsoBuP and $97-140 \mathrm{ng}^{-1}$ for TCC). MeP accounted for $66 \%$ of total parabens against $15 \%$ for PrP and EtP and less than $4 \%$ for $\mathrm{BuP}$ and IsoBuP. These results were in accordance with both the common paraben patterns reported in literature and paraben uses in personal care products. Indeed, $\mathrm{MeP}, \mathrm{EtP}$ and $\mathrm{PrP}$ are the most commonly used congeners owing to their solubility in comparison to long chain congeners. In France in 2009, about 7000 personal care products or formulations containing MeP were marketed against $3000-5000$ products containing the remaining paraben esters (Mintel database). Similarly, and as demonstrated by the ratio TCS / TCC evaluated in median at $29(19-52, \mathrm{~d} 10-\mathrm{d} 90)$, TCS is much more used than TCC. The production of each product in ton per year at the national scale is unfortunately not available.

Interestingly, MeP, EtP, PrP and BuP were correlated (Spearman test, $\alpha=0.05$, Supporting Table 5). This correlation could suggest i) these compounds are used in mixture in personal care products, or ii) the personal care products containing these pollutants are used at the same extent at the scale of the Parisian conurbation. No correlation was found between TCS and TCC or between this group and parabens probably reflecting different sources and consumption practices. Today, data are nevertheless too limited to draw a clear conclusion and further investigations are required. MeP and TCS are also significantly correlated to DOC, TKN 
and $\mathrm{NH}_{4}{ }^{+}$(Spearman test, $\left.\alpha=0.05\right)$, establishing a link between these pollutants and the human activities.

Table 2 provides a short review of concentrations found in wastewater for these chemicals (Andersen et al., 2007; Chen et al., 2012; Eriksson et al., 2009; Gonzalez-Marino et al., 2009; Halden and Paull, 2004; Jonkers et al., 2009; Kasprzyk-Hordern et al., 2008; Kumar et al., 2008; Kumar et al., 2010; Lozano et al., 2013; Wu et al., 2007; Yu et al., 2011). Globally and despite some methodological differences concerning the phases studied, the MeP and EtP concentrations found in this study lay in the upper range of concentrations reported in the literature while $\mathrm{PrP}, \mathrm{BuP}$ and IsoBuP ranges lay in the middle and middle low region of the literature interval. In spite of the dilution of Parisian wastewater by parasite waters (streetcleaning water, infiltration and leakage from the drinking water network as reported by Gasperi et al., 2008b), the concentrations found are far higher than those reported in greywater (Eriksson et al., 2009), in Switzerland (Jonkers et al., 2009), in Canada (Lee et al., 2005) or more recently in US (Yu et al., 2011), but are slightly higher than levels quoted by Kasprzyk-Hordern et al. (2009) in UK and by Andersen et al. (2007) in Denmark. Extremely low concentrations are reported in China (Chen et al., 2012). Except for Yu et al. (2011), Kasprzyk-Hordern et al. (2009) and Chen et al. (2012) who analyzed both dissolved and particulate phases, it should be mentioned that the other studies only consider the dissolved fraction (Table 3).

For TCS, a similar trend is also observed with concentrations lying in the middle-upper range of concentration reported in literature. Hence, TCS concentrations were globally similar to those reported by Halden and Paull (2005), Kumar et al. (2010) or Lozano et al. (2013) in US but far higher than those reported in Germany, UK or Spain (Table 2). In a review, TCS concentration range in influent from municipal WWTP varied from 220 to $7000 \mathrm{ng} \mathrm{l}^{-1}$, median value being $1900 \mathrm{ng} \mathrm{l}^{-1}$ (Verlicchi et al., 2012). Kumar et al. (2010) is the sole study reporting a similar TCS/TCC ratio than for Parisian wastewater. 
Whatever the compound under consideration, this short comparison with the literature data highlighted both geographic disparities and some potential difference of awareness in different countries as regard personal care products. This involves and confirms the need of monitoring program for these compounds at the French national scale.

Whatever the sewer trunk under consideration, concentrations slightly vary from campaign to campaign. The relative standard deviation (RSD), for all campaigns and sites, do not exceed $25 \%$. This weak variability is mainly related to the scale considered. Actually, our approach at a large scale allows a smoothing or buffering of the quality of wastewater.

As regards the spatial variability, the quality of wastewater is quite homogenous among sewer trunks for parabens. Some slight but no significant differences appear for SAN and SAR trunks, indeed both sites presented lower concentrations (-20\% in comparison to mean value), and SDA trunk with higher levels $(+27 \%)$. These differences could be linked to a more or less dilution of wastewater by parasite waters depending on the catchment considered. The dilution of the Parisian wastewater is actually known as demonstrated by Gasperi et al. (2008) and can vary depending on the sewer trunk considered. To confirm this hypothesis, the concentrations were normalized to TKN, considered as a tracer of human emission (Figure 2). Since for normalized concentrations, the differences are less marked among the sewer trunks, this confirms that the initial observed differences for concentrations are partially due to the wastewater dilution. The higher normalized concentrations of parabens for SDA trunk could be probably due to higher inputs. For TCS, higher concentrations are observed in MAV and SAM trunks. Such trend is not observed for TCC.

\subsection{Partitioning of pollutants between dissolved and particulate phase}

Table 3 summarizes the pollutant contents (in $\mathrm{mg} \mathrm{kg}^{-1}$ ), as well as the distribution coefficients $\left(\mathrm{K}_{\mathrm{D}}, 1 \mathrm{~kg}^{-1}\right)$ and the organic carbon-water partitioning coefficients $\left(\mathrm{K}_{\mathrm{OC}}\right)$ for all sewer trunks and field campaigns $(\mathrm{n}=28)$. Median values as well as first and last percentiles are 
provided. TCC was only detected in particulate phase and its partitioning was hence not evaluated. Few studies reported the partitioning of such chemicals in wastewater, and to our knowledge no study provides $\mathrm{K}_{\mathrm{D}}$ and $\mathrm{K}_{\mathrm{OC}}$ values for these compounds in wastewater. Interestingly and in spite of the octanol-water coefficient range $\left(1.96<\log \mathrm{K}_{\mathrm{OW}}<3.57\right)$, parabens are mainly associated to the dissolved fraction (>97\%). This low affinity for particles leads to i) low contents $\left(0.20 \mathrm{mg} \mathrm{kg}^{-1}\right.$ for MeP $0.01-0.04 \mathrm{mg} \mathrm{kg}^{-1}$ for the others parabens in median) and ii) $\operatorname{low} \log \mathrm{K}_{\mathrm{D}}\left(0.78-2.091 \mathrm{~kg}^{-1}\right)$ and $\log \mathrm{K}_{\mathrm{OC}}$ values $(1.19-2.42)$. TCS revealed a stronger affinity for particles as demonstrated by the higher contents (10.44 $\mathrm{mg} \mathrm{kg}^{-1}$, Table 3$)$ and higher $\log \mathrm{K}_{\mathrm{D}}\left(3.991 \mathrm{~kg}^{-1}\right.$ in median) and $\log \mathrm{K}_{\mathrm{OC}}$ (4.35) values. In spite of the matrix difference, the $\log \mathrm{K}_{\mathrm{D}}$ for primary $\left(3.2-3.31 \mathrm{~kg}^{-1}\right)$ and secondary $\left(2.7-3.21 \mathrm{~kg}^{-1}\right)$ sludges estimated in municipal WWTP in Greece (Stasinakis et al., 2013) were close. For TCS, dissolved phase account for $68 \pm 13 \%$. This is in accordance with the partitioning quoted by Kumar et al. (2010) or results reported in Greek wastewater (Stasinakis et al., 2008). In US, Kumar et al. (2010) also indicated that the dissolved phase account between 32.8 and $86.9 \%$ for TCS. The contents of TCS are in good accordance with those reported in Greece (1.1 - 37 $\mathrm{mg} \mathrm{kg}^{-1}$ ) (Gatidou et al., 2007) or in US (1.4 - $48 \mathrm{mg} \mathrm{kg}^{-1}$ ) (Kumar et al., 2010). No study reports contents for parabens.

\subsection{Loads per population equivalent}

Paraben, triclosan and triclocarban mass loads per PE and per day are reported in Figure 3. Based on all campaigns $(n=28)$, median mass loads were respectively estimated about 760 and $26 \mu \mathrm{g} \mathrm{PE}^{-1} \mathrm{~d}^{-1}$ for TCS and TCC and median mass loads vary between 30 and $3040 \mu \mathrm{g} \mathrm{PE}^{-}$ ${ }^{1} \mathrm{~d}^{-1}$ for parabens, i.e., MeP $\left(3040 \mu \mathrm{g} \mathrm{PE} \mathrm{P}^{-1} \mathrm{~d}^{-1}\right)$, EtP $\left(750 \mu \mathrm{g} \mathrm{PE} \mathrm{PE}^{-1} \mathrm{~d}^{-1}\right), \operatorname{PrP}\left(710 \mu \mathrm{g} \mathrm{PE}^{-1} \mathrm{~d}^{-1}\right)$, $\operatorname{IsoBuP}\left(30 \mu \mathrm{g} \mathrm{PE} \mathrm{P}^{-1}\right)$ and $\operatorname{BuP}\left(180 \mu \mathrm{g} \mathrm{PE} \mathrm{P}^{-1} \mathrm{~d}^{-1}\right)$.

For parabens, TCS and TCC, the comparison with French studies is not possible since no data are available. Based on an accounting of products containing parabens with industries, 
Masset (2007) estimated the French paraben use reach about $4000 \mathrm{t} \mathrm{y}^{-1}$, corresponding to a daily consumption about $144000 \mu \mathrm{g}$ inhab ${ }^{-1} \mathrm{~d}^{-1}$ for the main parabens (MeP, EtP and PrP, (Masset, 2007)). This assumption is far higher than the experimental results $(3800-6500 \mu \mathrm{g}$ $\mathrm{PE}^{-1} \mathrm{~d}^{-1}$ ) found in this study, demonstrating the difficulties to gain reliable data on the consumption of parabens and/or on the link between the paraben uses and the quality of wastewater.

To date, only Eriksson et al. (2009) provided paraben mass loads for greywater based on experiments on 120-resident building. These mass loads were respectively estimated at 275, 130, 140, 30 and $65 \mu \mathrm{g}$ inhab $^{-1} \mathrm{~d}^{-1}$ for MeP, EtP, PrP, IsoBuP and BuP; they are far lower than those calculated in our study. Two hypotheses could explain these differences. First, alone greywater (showers and hand wash basins) were considered by Eriksson et al. (2009), i.e., 431 inhab $\mathrm{d}^{-1} \mathrm{~d}^{-1}$ while raw wastewater were considered in this study. For reference, at the Parisian sewer scale, water consumption was estimated about $1601 . i n h a b^{-1} \mathrm{~d}^{-1}$ according to the local water utility Compagnie des eaux de Paris (Gasperi et al., 2008b) and showers and hand wash basins account for $20-30 \%$ of the daily volume, i.e., 32-48 1.inhab ${ }^{-1} \mathrm{~d}^{-1}$. This suggests that blackwater could be also contaminated by parabens. This contamination can be linked to the human emission via urine (Ye et al., 2006), sanitary cleaning products or other discharges into water closet (emptying a scouring pail, other cleaning products, etc.). The differences could also result from different practices and/or a higher concern of these chemicals leading to a lower consumption of personal care products containing paraben in Denmark in comparison to France. Besides, on 2011, Denmark introduced a national ban on parabens in cosmetic products intended for children under 3 years.

For TCS, some studies reported mass loads in Europe or in US. Wind (2004) in Germany estimated TCS mass loads about $1370 \mu \mathrm{g}$ inhab ${ }^{-1} \mathrm{~d}^{-1}$, on the basis of annual national consumption. This load is twice higher than the ones established in this study. The difference 
could reflect both i) the difficulties to estimate the real consumption at a national scale and ii) the consumption decrease of products containing triclosan between 2004 and 2010 because of the awareness of the hazards such compound may represent. This evolution could also explain the significant differences between the mass loads in this study and those reported by Halden and Paull (2004) in US, i.e., 3096 and $2822 \mu \mathrm{g}$ inhab $^{-1} \mathrm{~d}^{-1}$ for TCS and TCC. Median mass load for TCS $\left(762 \mu \mathrm{g} \mathrm{PE} \mathrm{PE}^{-1} \mathrm{~d}^{-1}\right)$ is also far higher than those reported in Switzerland or in Sweden, even if these studies were carried out earlier (Lindstrom et al., 2002; Palmquist and Hanæus, 2005). In Switzerland, Lindström et al. (2002) quoted TCS mass loads at $412 \mu \mathrm{g}$ inhab ${ }^{1} \mathrm{~d}^{-1}\left(190-750 \mu \mathrm{g}\right.$ inhab $\left.{ }^{-1} \mathrm{~d}^{-1}\right)$. In Sweden, Palmquist and Hanaeus (2005) evaluated about 200 $\mu \mathrm{g} \mathrm{PE} \mathrm{d}^{-1} \mathrm{~d}^{-1}$ in greywater and $100 \mu \mathrm{g} \mathrm{PE}^{-1} \mathrm{~d}^{-1}$ in blackwater. As for parabens, this may reflect geographical differences of consumption and practices as regards personal care products.

\subsection{Extrapolation at the national scale}

Based on the previous results, the national mass loads of parabens, TCS and TCC are provided in Table 4 according to calculation methods previously described. Globally, both methods gave mass loads in the same order of magnitude. For MeP, the annual national mass loads were in the $51.8-98.1 \mathrm{t} \mathrm{yr}^{-1}$ (d10-d90, method 1 , based on the daily mass load per PE, $\mathrm{n}=28$ ) or $78.2-100.6 \mathrm{t} \mathrm{yr}^{-1}$ (min-max, method 2, based on 4 campaigns) ranges. For TCS, median mass loads were respectively estimated at 18.2 and $19.9 \mathrm{t} \mathrm{y}^{-1}$ using methods 1 and 2 . To compare, Singer et al. (2002) estimated that about 350 t of TCS are annually produced for commercial applications (Singer et al., 2002), while in USA, more than $300 \mathrm{t} \mathrm{yr}^{-1}$ of TCS are estimated to be disposed into wastewater (Halden and Paull, 2005). At the national scale, such data are extremely relevant and innovative since this study is one of the first to report national mass loads for these chemicals. Nevertheless, no data on the paraben, TCS and TCC market or production are to date available to compare and to consolidate our results. 


\section{Conclusions}

This study was launched with the objectives of examining the occurrence and concentration ranges of parabens, TCS and TCC in wastewater at the scale of the Parisian sewer network and for providing representative knowledge on these compounds in developed countries such as France and for a large area. In this context, this innovative approach delivers some interesting findings.

For the first time, this study evaluated the pollutant mass loads per population equivalent of parabens, TCS and TCC at the large and representative scale of the Parisian sewer network. Hence, the median mass loads vary from 176 to $3039 \mu \mathrm{g} \mathrm{PE}^{-1} \mathrm{~d}^{-1}$ for parabens and from 26 to 762 for TCS and TCC (minimum and maximum median mass loads, depending on the compound). Based on these results and according to the assumption done, the extrapolation of the mass loads at the national scale points out an annual mass loads between 51.8 and $100.7 \mathrm{t}$ $\mathrm{y}^{-1}$ for MeP and between 11.2 and $23.5 \mathrm{t} \mathrm{y}^{-1}$ for TCS (extreme values according both methods). Mass loads per equivalent habitant and national mass loads are both extremely relevant and innovative data. At a national scale, geographic disparities between Paris and others regions in France are expected to be weak. Nevertheless, the question of the representativeness of French consumption to other developed countries raise. Contrary to other countries, such data are nowadays rather difficult to gain in France and no enquiry or database provides access to all of the information on the use and production of these chemicals. Since cosmetic industries are voluntarily and fully engaged in the substitution of parabens in personal care product, this study could constitute a "time reference status" which could be used as a basis for future monitoring. Hence, changes in practice could be studied.

In pursuit of this work, the amount of personal care products could be estimated at the Parisian or French scales according to different chemical composition assumptions or established regulation. Hence, mass loads of other pollutants contained in personal care 
products such as musk, fragrance, emulsifying agents, other types of preservatives or additives or nanoparticles could be hence evaluated. Based on the reviews quoting the WWTP efficiencies for these chemicals, mass loads of parabens, TCS and TCC discharged in the receiving water could be also assessed in order to better determine the potential risk of these chemicals on aquatic organisms.

\section{Acknowledgments}

This study was carried out within the framework of the OPUR research program. Authors gratefully acknowledge the Paris public sanitation service (SIAAP) for their technical support during this study.

\section{References}

Andersen HR, Lundsbye M, Wedel HV, Eriksson E, Ledin A. Estrogenic personal care products in greywater reuse system. Water Science and Technology 2007; 56: 45-49.

Bedoux G, Roig B, Thomas O, Dupont V, Le Bot B. Occurrence and toxicity of antimicrobial triclosan and by-products in the environment. Environmental Science and Pollution Research 2012; 19: 1044-1065.

Berge A, Cladiere M, Gasperi J, Coursimault A, Tassin B, Moilleron R. Meta-analysis of environmental contamination by phthalates. Environmental science and pollution research international 2013; 20: 8057-76.

Chen ZF, Ying GG, Lai HJ, Chen F, Su HC, Liu YS, et al. Determination of biocides in different environmental matrices by use of ultra-high-performance liquid chromatographytandem mass spectrometry. Analytical and Bioanalytical Chemistry 2012; 404: 31753188 .

Eriksson E, Andersen HR, Madsen TS, Ledin A. Greywater pollution variability and loadings. Ecological Engineering 2009; 35: 661-669.

Gasperi J, Garnaud S, Rocher V, Moilleron R. Priority pollutants in wastewater and combined sewer overflow. Science of the Total Environment 2008a; 407: 263-272.

Gasperi J, Kafi-Benyahia M, Lorgeoux C, Moilleron R, Gromaire MC, Chebbo G. Spatial variability of the pollutant load conveyed by dry weather flows within the Parisian combined sewers. Urban Water Journal 2008b; 5: 305-314.

Gatidou G, Thomaidis NS, Stasinakis AS, Lekkas TD. Simultaneous determination of the endocrine disrupting compounds nonylphenol, nonylphenol ethoxylates, triclosan and 
bisphenol $\mathrm{A}$ in wastewater and sewage sludge by gas chromatography-mass spectrometry. Journal of Chromatography A 2007; 1138: 32-41.

Geara-Matta D. Loads and sources of parabens, triclosan and triclocarban in urban aeras: case study of Paris and Beirut. PhD Thesis, University Paris-Est, Environmental Sciences (in French), 2012, pp. 181.

Geara-Matta D, Lorgeoux C, Rocher V, El Samrani A, Chebbo G, Moilleron R. Occurrence of endocrine disruptors in wastewater from combined sewers in Paris and Beirut: what about parabens?, 12th International Conference on Urban Drainage, Porto Alegre (Brazil), 2011, pp. 8.

Gonzalez-Marino I, Benito Quintana J, Rodriguez I, Cela R. Simultaneous determination of parabens, triclosan and triclocarban in water by liquid chromatography/electrospray ionisation tandem mass spectrometry. Rapid Communications in Mass Spectrometry 2009; 23: 1756-1766.

Gracia-Lor E, Sancho JV, Serrano R, Hernandez F. Occurrence and removal of pharmaceuticals in wastewater treatment plants at the Spanish Mediterranean area of Valencia. Chemosphere 2012; 87: 453-462.

Halden RU, Paull DH. Analysis of triclocarban in aquatic samples by liquid chromatography electrospray ionization mass spectrometry. Environmental Science \& Technology 2004; 38: 4849-4855.

Halden RU, Paull DH. Co-Occurrence of Triclocarban and Triclosan in U.S. Water Resources. Environmental Science \& Technology 2005; 39: 1420-1426.

Halling-Sorensen B, Nielsen SN, Lanzky PF, Ingerslev F, Lutzhoft HCH, Jorgensen SE. Occurrence, fate and effects of pharmaceutical substances in the environment - A review. Chemosphere 1998; 36: 357-394.

Jonkers N, Kohler H-PE, Dammshäuser A, Giger W. Mass flows of endocrine disruptors in the Glatt River during varying weather conditions. Environmental Pollution 2009; 157: 714-723.

Kasprzyk-Hordern B, Dinsdale RM, Guwy AJ. Multiresidue methods for the analysis of pharmaceuticals, personal care products and illicit drugs in surface water and wastewater by solid-phase extraction and ultra performance liquid chromatographyelectrospray tandem mass spectrometry. Analytical and Bioanalytical Chemistry 2008; 391: 1293-1308.

Kasprzyk-Hordern B, Dinsdale RM, Guwy AJ. The removal of pharmaceuticals, personal care products, endocrine disruptors and illicit drugs during wastewater treatment and its impact on the quality of receiving waters. Water Research 2009; 43: 363-380.

Kolpin DW, Furlong ET, Meyer MT, Thurman EM, Zaugg SD, Barber LB, et al. Pharmaceuticals, Hormones, and Other Organic Wastewater Contaminants in U.S. Streams, A National Reconnaissance. Environmental Science \& Technology 2002; 36: 1202-1211. 
Kumar A, Peck AM, Palefsky W, Sajwan KS. Clearing rate and mass loadings of triclosan and triclocarban in four wastewater treatment plants in Savannah, Georgia, USA. Organohalogen Compound 2008; 70: 233-236.

Kumar KS, Priya SM, Peck AM, Sajwan KS. Mass Loadings of Triclosan and Triclocarbon from Four Wastewater Treatment Plants to Three Rivers and Landfill in Savannah, Georgia, USA. Archives of Environmental Contamination and Toxicology 2010; 58: 275-285.

Lee HB, Peart TE, Svoboda ML. Determination of endocrine-disrupting phenols, acidic pharmaceuticals, and personal-care products in sewage by solid-phase extraction and gas chromatography-mass spectrometry. Journal of Chromatography A 2005; 1094: 122-129.

Lindstrom A, Buerge IJ, Poiger T, Bergqvist P-A, Muller MD, Buser H-R. Occurrence and Environmental Behavior of the Bactericide Triclosan and Its Methyl Derivative in Surface Waters and in Wastewater. Environmental Science \& Technology 2002; 36: 2322-2329.

Liu JL, Wong MH. Pharmaceuticals and personal care products (PPCPs): A review on environmental contamination in China. Environment International 2013; 59: 208-224.

Lozano N, Rice CP, Ramirez M, Torrents A. Fate of Triclocarban, Triclosan and Methyltriclosan during wastewater and biosolids treatment processes. Water Research 2013; 47: 4519-4527.

Masset D. La sécurité des excipiants : études de cas (Safety excipiants: case studies). Congrès de la société française de Toxicologie (Congress of the French Society of Toxicology), Montepellier (France), 2007 (in french), http://www.sftox.com/congres/sft2007/conf/SFT2007_D_Masset.pdf., 2007.

Miege C, Choubert JM, Ribeiro L, Eusebe M, Coquery M. Fate of pharmaceuticals and personal care products in wastewater treatment plants - Conception of a database and first results. Environmental Pollution 2009; 157: 1721-1726.

Mintel. Global Market Research and Market Insight, http://www.mintel.com. September 2013, 2013.

Onesios KM, Yu JT, Bouwer EJ. Biodegradation and removal of pharmaceuticals and personal care products in treatment systems: a review. Biodegradation 2009; 20: 441-466.

Palmquist H, Hanæus J. Hazardous substances in separately collected grey- and blackwater from ordinary Swedish households. Science of the Total Environment 2005; 348: 151163.

Paxeus N. Organic pollutants in the effluents of large wastewater treatment plants in Sweden. Water Research 1996; 30: 1115-1122.

SCCS. Opinion on parabens - Updated request for a scientific opinion on propyl- and butylparaben - COLIPA n ${ }^{\circ}$ P82. In: European Union, editor, 2013, pp. 82. 
Sim W-J, Lee J-W, Oh J-E. Occurrence and fate of pharmaceuticals in wastewater treatment plants and rivers in Korea. Environmental Pollution 2010; 158: 1938-1947.

Singer H, Muller S, Tixier C, Pillonel L. Triclosan: Occurrence and fate of a widely used biocide in the aquatic environment: Field measurements in wastewater treatment plants, surface waters, and lake sediments. Environmental Science \& Technology 2002; 36: 4998-5004.

Stasinakis AS, Gatidou G, Mamais D, Thomaidis NS, Lekkas TD. Occurrence and fate of endocrine disrupters in Greek sewage treatment plants. Water Research 2008; 42: 17961804.

Stasinakis AS, Thomaidis NS, Arvaniti OS, Asimakopoulos AG, Samaras VG, Ajibola A, et al. Contribution of primary and secondary treatment on the removal of benzothiazoles, benzotriazoles, endocrine disruptors, pharmaceuticals and perfluorinated compounds in a sewage treatment plant. Science of the Total Environment 2013; 463: 1067-1075.

Tavares RS, Martins FC, Oliveira PJ, Ramalho-Santos J, Peixoto FP. Parabens in male infertility-Is there a mitochondrial connection? Reproductive Toxicology 2009; 27: 17.

Thoburn B. Kjeldhal, the man, the method and the Carlsberg laboratory. Analytical Proceedings 21, 210-214. Analytical Proceedings 1984; 21: 210-214.

Verlicchi P, Al Aukidy M, Zambello E. Occurrence of pharmaceutical compounds in urban wastewater: Removal, mass load and environmental risk after a secondary treatment-A review. Science of the Total Environment 2012; 429: 123-155.

Vienneras B. Faecal Separation and Urine Diversion of Nutrient Management of Household Biodegradation Waste and Wastewater. $\mathrm{PhD}$ thesis, Institutionen för lantbruksteknik. PhD. Swedish University of Agricultural Sciences, 2001, pp. 325.

Wind T, Werner U, Jacob M, Hauk A. Environmental concentrations of boron, LAS, EDTA, NTA and Triclosan simulated with GREAT-ER in the river Itter. Chemosphere 2004; 54: $1135-1144$.

Wu J-L, Lam NP, Martens D, Kettrup A, Cai Z. Triclosan determination in water related to wastewater treatment. Talanta 2007; 72: 1650-1654.

Ye X, Bishop AM, Reidy JA, Needham LL, Calafat AM. Parabens as urinary biomarkers of exposure in humans. Environmental Health Perspectives 2006; 114: 1843-1846.

Yu Y, Huang Q, Wang Z, Zhang K, Tang C, Cui J, et al. Occurrence and behavior of pharmaceuticals, steroid hormones, and endocrine-disrupting personal care products in wastewater and the recipient river water of the Pearl River Delta, South China. Journal of Environmental Monitoring 2011; 13: 871-878. 


\section{Figure caption}

Figure 1: Map of the Parisian sewer network and location of the sewer trunks studied ..................................... 22

Figure 2: Total concentrations (mean $\pm \mathrm{SD}$, including dissolved + particulate phases) of parabens, TCC and TCS

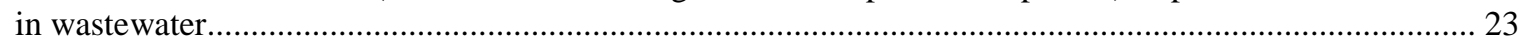

Figure 3: Loads per population equivalent $\left(\mu \mathrm{g} \mathrm{PE}^{-1} \mathrm{~d}^{-1}\right.$, mean $\left.\pm \mathrm{SD}\right)$ of parabens, TCC and TCS in wastewater 24 


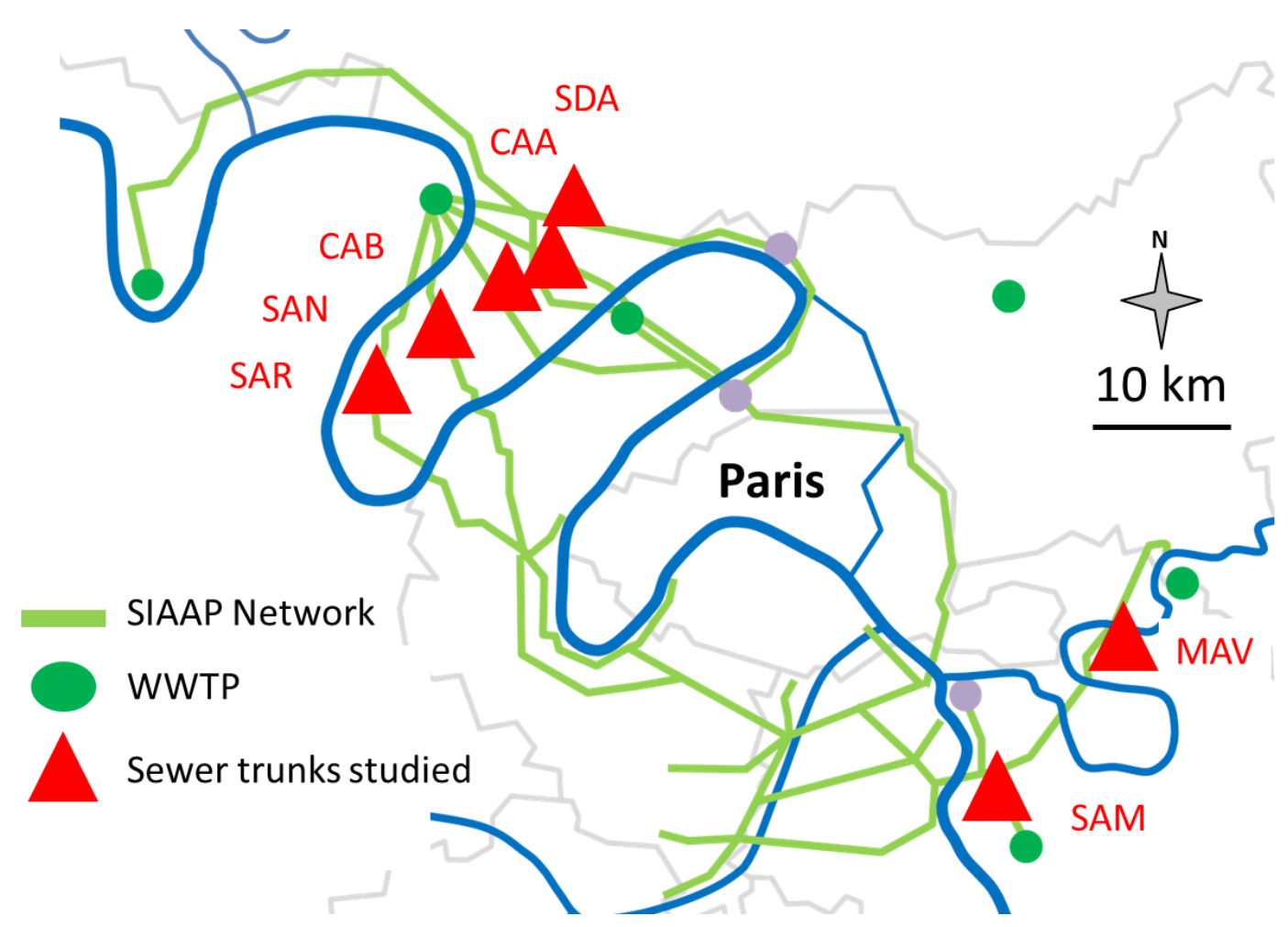

Figure 1: Map of the Parisian sewer network and location of the sewer trunks studied 

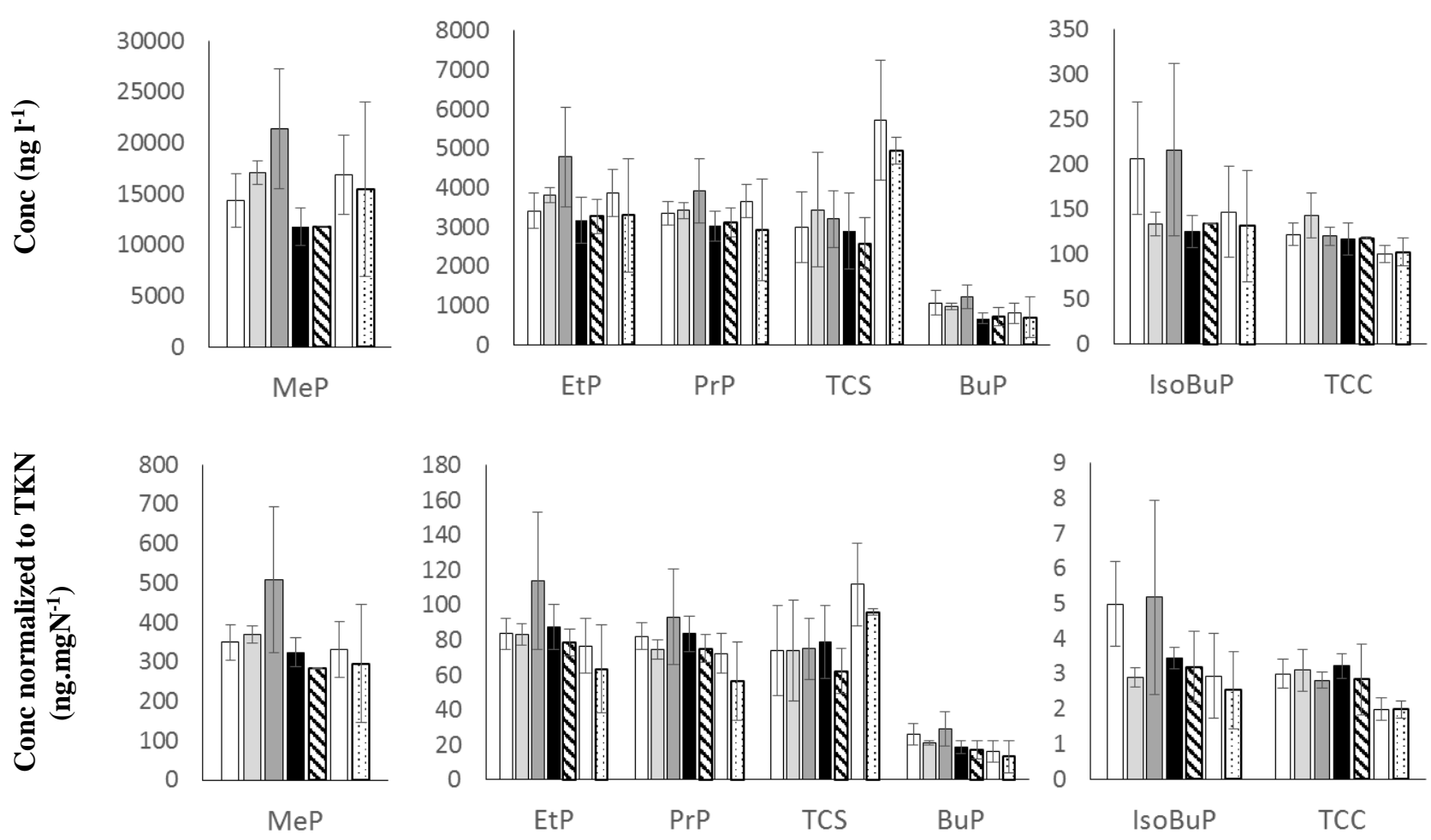

From left to right: 1) $C A B$, 2) $C A A$, 3) $S D A$, 4) $S A N$, 5) $S A R$, 6) MAV and 7) SAM

Figure 2: Total concentrations (mean \pm SD, including dissolved + particulate phases) of parabens, TCC and TCS in wastewater 

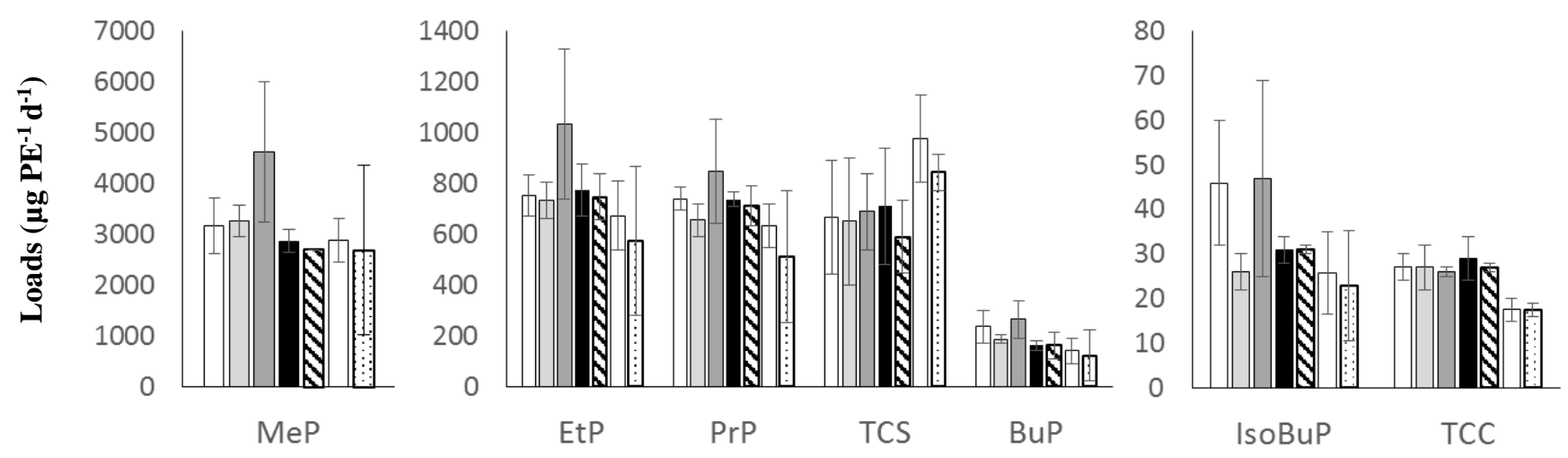

From left to right: 1) $C A B, 2) C A A, 3) S D A, 4) S A N$, 5) $S A R$, 6) MAV and 7) SAM

Figure 3: Loads per population equivalent $\left(\mu \mathrm{PE}^{-1} \mathrm{~d}^{-1}\right.$, mean $\left.\pm \mathrm{SD}\right)$ of parabens, TCC and TCS in wastewater 


\section{Table caption}

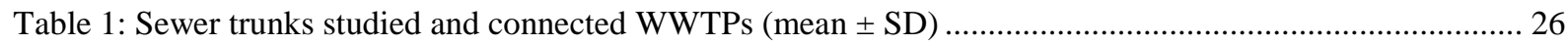

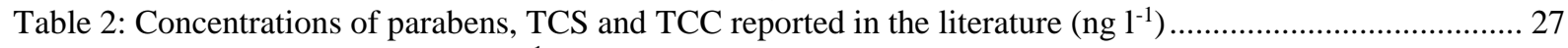

Table 3: Contents of particles $\left(\mathrm{mg} \mathrm{kg}^{-1}\right), \log \left(\mathrm{K}_{\mathrm{d}}\right)$ and $\log \left(\mathrm{K}_{\mathrm{OC}}\right)$ for parabens, TCS and TCC …...................... 28

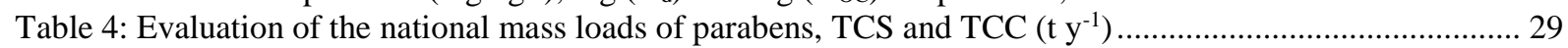


Table 1: Sewer trunks studied and connected WWTPs (mean \pm SD)

\begin{tabular}{|c|c|c|c|c|c|c|}
\hline Trunks & WWTP & $\begin{array}{c}\text { Flow } \\
\left(\mathrm{m}^{3} \mathbf{d}^{-1}\right)\end{array}$ & PE* & $\begin{array}{c}\text { TSS } \\
\left(\mathrm{mg.l}^{-1}\right)\end{array}$ & $\begin{array}{c}\text { DOC } \\
\left(\mathrm{mgC.}^{-1}\right)^{-1}\end{array}$ & $\begin{array}{c}\text { TKN } \\
\left(\mathrm{mgN} \mathbf{l}^{-1}\right)\end{array}$ \\
\hline Saint-Denis Achères (SDA) & Seine Aval & $249000 \pm 110000$ & $1173200 \pm 575000$ & $219 \pm 68$ & $38 \pm 7$ & $56 \pm 3$ \\
\hline Clichy Achères Argenteuil (CAA) & Seine Aval & $458000 \pm 39300$ & $2390000 \pm 172000$ & $239 \pm 98$ & $58 \pm 10$ & $63 \pm 3$ \\
\hline Clichy Achères Bezons (CAB) & Seine Aval & $274000 \pm 48900$ & $1234400 \pm 210000$ & $189 \pm 85$ & $43 \pm 3$ & $54 \pm 2$ \\
\hline Sèvres Achères Nanterre (SAN) & Seine Aval & $53000 \pm 42000$ & $225900 \pm 207000$ & $178 \pm 35$ & $27 \pm 5$ & $49 \pm 7$ \\
\hline Sèvres Achères Rueil (SAR) & Seine Aval & $418000 \pm 12800$ & $1830000 \pm 27450$ & $214 \pm 67$ & $30 \pm 3$ & $53 \pm 1$ \\
\hline Marne Aval (MAV) & Marne Aval & $49500 \pm 4600$ & $290000 \pm 37200$ & $392 \pm 34$ & $51 \pm 5$ & $70 \pm 8$ \\
\hline Seine Amont (SAM) & Seine Amont & $398000 \pm 48500$ & $2350000 \pm 375000$ & $368 \pm 43$ & $45 \pm 7$ & $70 \pm 5$ \\
\hline Total $* *$ & & $1900000 \pm 79400$ & $9485000 \pm 581900$ & & & \\
\hline
\end{tabular}

* PE = population equivalent calculated according to dissolved TKN nitrogen, ** Total = total volume flowing in a day along the 7 selected trucks and the total PE 
Table 2: Concentrations of parabens, TCS and TCC reported in the literature (ng $\left.\mathbf{l}^{-1}\right)$

\begin{tabular}{|c|c|c|c|c|c|c|c|c|c|}
\hline Reference & Country & Phase* & MeP & EtP & PrP & IsoBuP & BuP & TCS & TCC \\
\hline $\begin{array}{c}\text { This study* (d10-d90) } \\
\text { Median }\end{array}$ & France & $\mathrm{D}+\mathrm{P}$ & $\begin{array}{c}10300-20100 \\
15000 \\
\end{array}$ & $\begin{array}{c}2670-4670 \\
3610 \\
\end{array}$ & $\begin{array}{c}2440-3980 \\
3340 \\
\end{array}$ & $\begin{array}{c}98-230 \\
130 \\
\end{array}$ & $\begin{array}{c}450-1280 \\
870 \\
\end{array}$ & $\begin{array}{c}2140-5260 \\
3450 \\
\end{array}$ & $\begin{array}{c}97-140 \\
110 \\
\end{array}$ \\
\hline Halden and Paull (2005)** & US & $\mathrm{D}+\mathrm{P}$ & & & & & & $6100 \pm 1600$ & $6700 \pm 100$ \\
\hline Lee et al. (2005) & Canada & $\mathrm{D}$ & $100-1470$ & $20-270$ & $200-2430$ & - & $20-260$ & $870-1830$ & \\
\hline Wu et al. (2007) & Germany & $\mathrm{T}$ & & & & & & $142-214$ & \\
\hline Andersen et al. (2007) & Denmark & $\mathrm{D}$ & $7600-17600$ & $3250-3950$ & $\begin{array}{l}7900-10 \\
700\end{array}$ & $770-1050$ & $1300-1900$ & & \\
\hline Kumar et al. (2008) & US & $\mathrm{D}$ & & & & & & $6178-38255$ & $157-1372$ \\
\hline Kasprzyk-Hordern et al. (2009) & UK & $\mathrm{D}+\mathrm{P}$ & $661-15646$ & $192-1948$ & $<2-1703$ & $<2-114$ & & $33-463$ & \\
\hline Jonkers et al. (2009) & Switzerland & $\mathrm{D}$ & $65-9880$ & $2.2-719$ & $43-1540$ & - & $9.7-864$ & & \\
\hline Eriksson et al. (2009) & Denmark & $\mathrm{D}$ & $100-3700$ & $<100-4100$ & $<100-2100$ & $100-8000$ & $200-1700$ & & \\
\hline Gonzalez-Marino et al. (2009) & Spain & $\mathrm{D}$ & $1926-5138$ & $452-549$ & $1147-1302$ & $83-86$ & $150-181$ & $<$ LOQ-936 & $<\mathrm{LOQ}$ \\
\hline Yu et al. (2011) & US & $\mathrm{D}+\mathrm{P}$ & $1002-1194$ & & & & & $712-2301$ & $1217-2354$ \\
\hline Chen et al. (2012) & China & $\mathrm{D}+\mathrm{P}$ & $347-397$ & $42.5-50.3$ & $63.1-75.3$ & & $4.6-5.4$ & $104-122$ & $249-285$ \\
\hline Stasinakis et al. (2008) & Greece & $\mathrm{D}+\mathrm{P}$ & & & & & & $170-23900$ & \\
\hline Lozano et al. (2013) & US & $\mathrm{D}+\mathrm{P}$ & & & & & & $7580-8520$ & $\begin{array}{l}920- \\
5 \\
920\end{array}$ \\
\hline
\end{tabular}

3 Phase studied: $D=$ dissolved, $P=$ particulate, $T=$ Total

$4 *$ this study $=$ first and last percentiles (d10 and d90), median value, ** Halden and Paull (2005) = mean \pm standard deviation

5 For other references, min and max values are provided. 
Table 3: Contents of particles $\left(\mathrm{mg} \mathrm{kg}^{-1}\right), \log \left(K_{d}\right)$ and $\log \left(K_{O O C}\right)$ for parabens, TCS and TCC

\begin{tabular}{lcccccccc}
\hline & & MeP & PrP & EtP & IsoBuP & BuP & TCS & TCC \\
\hline Log Kow & & 1.96 & 3.04 & 2.47 & 3.27 & 3.57 & 4.76 & 4.90 \\
\hline Contents & d10-d90 & $0.14-0.29$ & $0.02-0.06$ & $0.02-0.12$ & $0.01-0.02$ & $0.02-0.06$ & $8.11-12.93$ & $0.12-0.28$ \\
& median & 0.20 & 0.02 & 0.04 & 0.01 & 0.03 & 10.44 & 0.17 \\
\hline Log $\mathrm{K}_{\mathrm{d}}$ & d10-d90 & $0.88-1.32$ & $0.67-1.30$ & $0.79-1.56$ & $1.81-2.18$ & $1.27-2.03$ & $3.74-4.18$ & \\
& median & 1.14 & 0.78 & 1.14 & 2.09 & 1.50 & 3.99 & \\
\hline Log KoC & d10-d90 & $1.22-1.69$ & $0.99-1.64$ & $1.13-1.89$ & $2.14-2.52$ & $1.64-2.36$ & $4.10-4.52$ & \\
& median & 1.50 & 1.19 & 1.46 & 2.42 & 1.83 & 4.35 & \\
\hline
\end{tabular}

$3 \quad d 10=$ first percentile, $d 90=$ last percentile

4

5 
Table 4: Evaluation of the national mass loads of parabens, TCS and TCC (t $\left.\mathbf{y}^{-1}\right)$

\begin{tabular}{|c|c|c|c|c|c|c|c|}
\hline & $\mathrm{MeP}$ & EtP & PrP & IsoBuP & $\mathrm{BuP}$ & TCS & $\mathrm{TCC}$ \\
\hline \multicolumn{8}{|l|}{ Method 1* } \\
\hline $\mathrm{d} 10-\mathrm{d} 90$ & $51.8-98.1$ & $11.7-22.7$ & $11.7-19.8$ & $0.5-1.2$ & $2.2-6.3$ & $11.2-23.5$ & $0.4-0.7$ \\
\hline median & 72.4 & 18.0 & 17.0 & 0.7 & 4.2 & 18.2 & 0.6 \\
\hline \multicolumn{8}{|l|}{ Method 2** } \\
\hline Min-max & $78.2-100.6$ & $18.7-23.4$ & $17.2-20.3$ & $0.7-1.0$ & $3.9-6.0$ & $18.8-22.0$ & $0.6-0.8$ \\
\hline mean & 86.8 & 20.3 & 18.5 & 0.9 & 5.0 & 19.9 & 0.7 \\
\hline
\end{tabular}

2 Method $1^{*}:$ median and d10-d90 values are provided since results are compiled $(n=28)$

3 Method 2**: the total mass loads were evaluated for the four campaigns carried out and then extrapolated to

4 the entire population: mean, min and max values are provided. 